\title{
Expression of Anti-apoptotic Protein BAG3 in Human Sebaceous Gland Carcinoma of the Eyelid
}

\author{
TATSUYA YUNOKI $^{1}$, YOSHIAKI TABUCHI $^{2}$ and ATSUSHI HAYASHI ${ }^{1}$ \\ ${ }^{1}$ Department of Ophthalmology, Graduate School of Medicine and Pharmaceutical Sciences, \\ University of Toyama, Toyama, Japan; \\ ${ }^{2}$ Division of Molecular Genetics Research, Life Science Research Center, University of Toyama, Toyama, Japan
}

\begin{abstract}
Background: Bcl-2-associated athanogene 3 (BAG3), a co-chaperone of heat shock protein 70 (HSP70), has been shown to play a role in anti-apoptosis of various malignant tumors. In this study, the expression of BAG3 was examined in human sebaceous gland carcinoma of the eyelid. Materials and Methods: The expression of BAG3 was evaluated by immunohistochemistry of surgical samples from 5 patients with sebaceous gland carcinoma in the eyelid. Results: BAG3 was positive diffusely in the cytoplasm in all patients. The average positive rate of BAG3 was $73.0 \pm 26.0 \%$ in tumor cells of all patients. Conclusion: BAG3 was highly expressed in sebaceous gland carcinoma of the eyelid. BAG3 may play an important role in the pathogenesis and progression of sebaceous gland carcinoma of the eyelid.
\end{abstract}

Sebaceous gland carcinoma of the eyelid is a highly aggressive malignant tumor that is relatively common in Asian countries, and it comprises about $30 \%$ of malignant eyelid tumors (1). The fundamental treatment for sebaceous gland carcinoma is surgical excision of the tumor, but it can exhibit aggressive local behavior and can metastasize to regional lymph nodes and distant organs (2). Furthermore, sebaceous gland carcinoma of the eyelid is often misdiagnosed as other benign and malignant lesions, thereby making early detection and treatment difficult (3). Successful management of eyelid sebaceous gland carcinoma is dependent on several factors, including tumor size $(4,5)$ and pagetoid spread (diffuse

This article is freely accessible online.

Correspondence to: Tatsuya Yunoki, Department of Ophthalmology, Graduate School of Medicine and Pharmaceutical Sciences, University of Toyama, 2630 Sugitani, Toyama 930-0194, Japan. Tel: +81 764347363, Fax: +81 764345037, e-mail: yunokiki@med.utoyama.ac.jp

Key Words: Sebaceous gland carcinoma, BAG3, immunohistochemistry. epithelial involvement) $(6,7)$. However, despite many efforts, the outcomes of patients are mostly unpredictable, and there are still few useful markers for predicting prognosis. Accordingly, research focused on predicting the risk of recurrence and the effectiveness of adjuvant therapy is valuable for the patients with sebaceous gland carcinoma of the eyelid.

Heat shock proteins (HSPs) function as molecular chaperones and exert cytoprotective effects. Among the HSPs, proteins from the HSP70 family play central roles as molecular chaperones. Bcl-2-associated athanogene 3 (BAG3) belongs to a family of co-chaperones that interacts with the ATPase domain of HSP70 (8). Although BAG3 is down-regulated in normal cells, it is upregulated in various malignant tumors (9-13). It has been reported that BAG3 plays a role in anti-apoptotic properties through pro-survival response to various stresses in cancer cells (14-16).

The relationships between human sebaceous gland carcinoma and BAG3 are poorly understood. In this study, we examined these relationships immunohistochemically in human surgically removed sebaceous gland carcinoma of the eyelid.

\section{Materials and Methods}

Patients and clinical materials. We enrolled 5 patients with sebaceous gland carcinoma of the eyelid between 2014 and 2016 at the Toyama University Hospital. All patients underwent surgical excision of the tumor. The tissues were fixed using $4 \%$ paraformaldehyde in phosphate-buffered saline. Paraffin-embedded tissues were stained with hematoxylin-eosin and examined immunohistochemically by the Pathology Institute Corporation (Toyama, Japan). All patient details are summarized in Table I. Our procedures conformed to the tenets of the World Medical Association's Declaration of Helsinki. Written informed consent was obtained from the patients after provision of sufficient information about the procedures.

Immunohistochemistry. The primary rabbit monoclonal BAG3 antibody (ab92309; Abcam, Cambridge, MA, USA) was used at a dilution of 1:400. Immunohistochemistry was performed using Leica BOND III automation and BOND Polymer Refine Detection System Kit (Leica Biosystems, Bannockburn, IL, USA). The protocol included in situ deparaffinization and high-pH epitope 
retrieval for $40 \mathrm{~min}$, primary antibody incubation for $20 \mathrm{~min}$, polymer for $8 \mathrm{~min}$, and $\mathrm{DAB}$ as the chromogen for $10 \mathrm{~min}$, followed by a 5 -min hematoxylin counterstaining.

BAG3 scoring. Positivity was graded by the membranous and cytoplasmic staining. Staining intensity was applied for the immunohistochemistry results: $3+$, strongly positive, $2+$, moderately positive, $1+$, weakly positive, and negative. The total amount of positive rate $(1+\sim 3+)$ was set as the tumor positive rate of the case.

\section{Results}

We examined the expression of BAG3 in surgically removed eyelid tissues from 5 patients with sebaceous gland carcinoma of the eyelid by immunohistochemistry. The clinical characteristics of patients are presented in Table I. Altogether, 5 patients were enrolled ( 1 male, 4 female; mean age $=76.8 \pm 8.0$ years, range 67-89=years; 4 with upper eyelid affected, one with lower eyelid affected). All patients had nodule-type tumors. The tumor category, as defined by the American Joint Committee on Cancer (AJCC) was T2a in 4 and T2b in 1. The mean followup period after surgery was $20.4 \pm 4.1$ months (range $=16-28$ months). In the follow-up period, there was 1 case of local recurrence and 1 case of metastasis to lymph nodes.

BAG3 was positive diffusely in the cytoplasm of all patients (Figure 1). However, the rate of BAG3 positivity differed by case. The positive rate for Case 1 and Case 2 was $100 \%$, and the positive rate of Cases $3-5$ was $80 \%, 45 \%$, $40 \%$, respectively. On average, the BAG3 positivity rate was $73.0 \% \pm 26.0 \%$ in all patients. Furthermore, the rate of strongly-positive was $10.0 \% \pm 13.0 \%$ (range $=0-35$ ), moderately-positive was $26.0 \% \pm 29.6 \%$ (range $0-80$ ), and weakly-positive was $37.0 \% \pm 23.1 \%$ (range $=0-60)$ (Table II).

\section{Discussion}

Sebaceous gland carcinoma of the eyelid is a high-grade malignancy that metastasizes to regional lymph nodes and distant organs (2). Chemotherapy has been used for metastatic sebaceous gland carcinoma, but it is not effective $(17,18)$. Accordingly, the study of sebaceous gland carcinoma-specific biomarkers is important for improving prognosis and treatment outcomes. In this study, we confirmed that anti-apoptotic protein BAG3 was highly expressed in sebaceous gland carcinoma of the eyelid histopathologically. To the best of our knowledge, this is the first report of the overexpression of BAG3 in the sebaceous gland carcinoma of the eyelid.

Previous reports have shown that overexpression of BAG3 was observed in human cancer cells of various origins (913), and it has been demonstrated that this overexpression is related to the development of cancer, invasiveness, metastasis, angiogenesis, tumor adhesion, migration, and resistance to chemotherapy (19-23). BAG3 shows anti-
Table I. Patient characteristics.

\begin{tabular}{lccccc}
\hline & Case 1 & Case 2 & Case 3 & Case 4 & Case 5 \\
\hline Age & 89 & 67 & 80 & 69 & 79 \\
Gender & F & M & F & F & F \\
Location & L & L & L & R & R \\
& upper & lower & upper & upper & upper \\
T category & T2a & T2a & T2a & T2a & T2b \\
Tumor pattern & nodule & nodule & nodule & nodule & nodule \\
Follow-up after & & & & & \\
surgery (months) & 20 & 28 & 20 & 16 & 18 \\
Local recurrence & - & - & - & + & - \\
Lymph node metastasis & - & - & - & - & + \\
\hline
\end{tabular}

F: Female, M: male, L: left, R: right.

apoptotic activity by interacting with different molecular partners, such as Bcl-2 family member BAX, Mcl-1, IKK $\gamma$, and $\operatorname{BRAF}(14-16,24,25)$. At present, the detailed molecular mechanisms underlying the relationship between BAG3 and sebaceous gland carcinoma of the eyelid are unknown. Upregulated BAG3 expression may contribute to apoptosisresistant properties through several mechanisms, and may become to a useful therapeutic strategy for anti-cancer therapy for patients with sebaceous gland carcinoma of the eyelid. We should validate molecular targets of BAG3 as a novel strategy though inhibition of BAG3. Further investigations will be needed to clarify this issue.

In this study, the rate of BAG3 positive rate varied by case. Case 1 and Case 2, in which the positive rate of BAG3 was $100 \%$, did not show local recurrence or lymph node metastasis. Several authors have reported that significant correlations between BAG3 protein levels and prognosis were observed $(26,27)$. Therefore, BAG3 overexpression may correlate with poor prognosis of patients with sebaceous gland carcinoma of the eyelid. However, the relationship between recurrence or metastasis and BAG3 positivity is not clear at present. Accordingly, we must examine more cases over a longer follow-up period.

In conclusion, BAG3 is overexpressed in human sebaceous gland carcinoma of the eyelid. Our findings suggest that BAG3 may offer a therapeutic target for patients with sebaceous gland carcinoma, and plays a role in the pathogenesis and progression of sebaceous gland carcinoma.

\section{Conflicts of Interest}

There is no conflict of interest.

\section{Acknowledgements}

This study was supported in part by a Grant-in-Aid for Young Scientists (B) (JP16K20309) from the Japan Society for the Promotion of Science. 
A

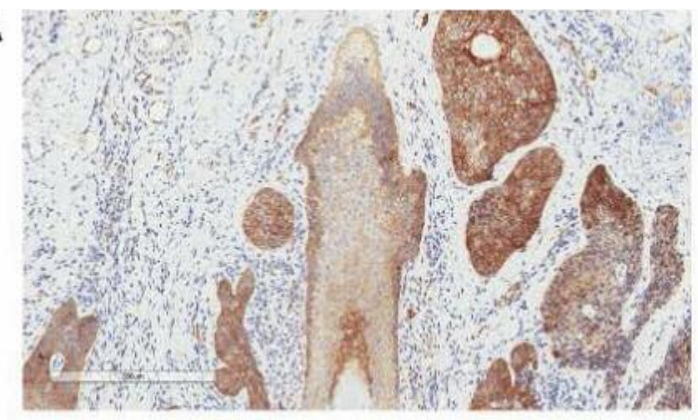

C

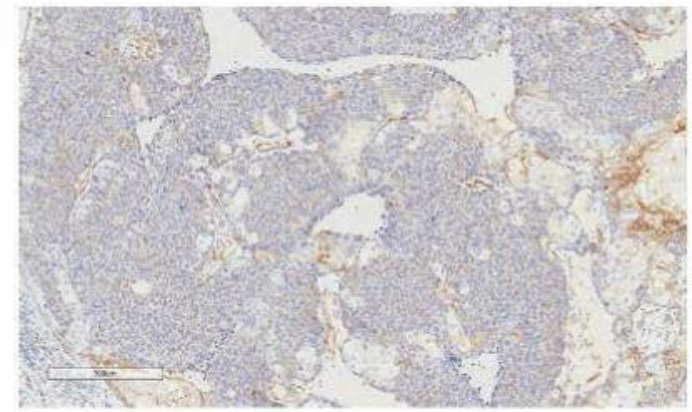

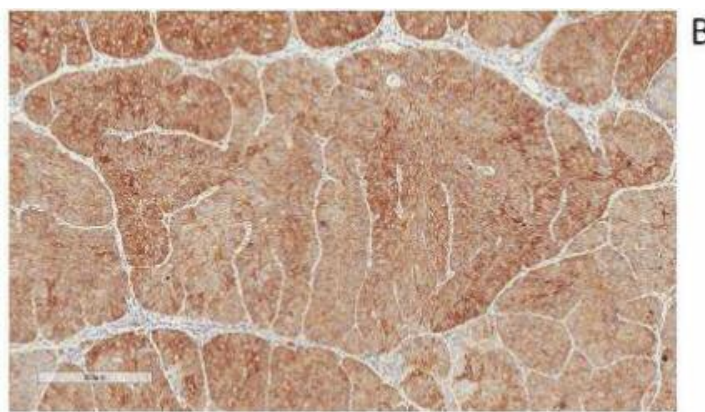
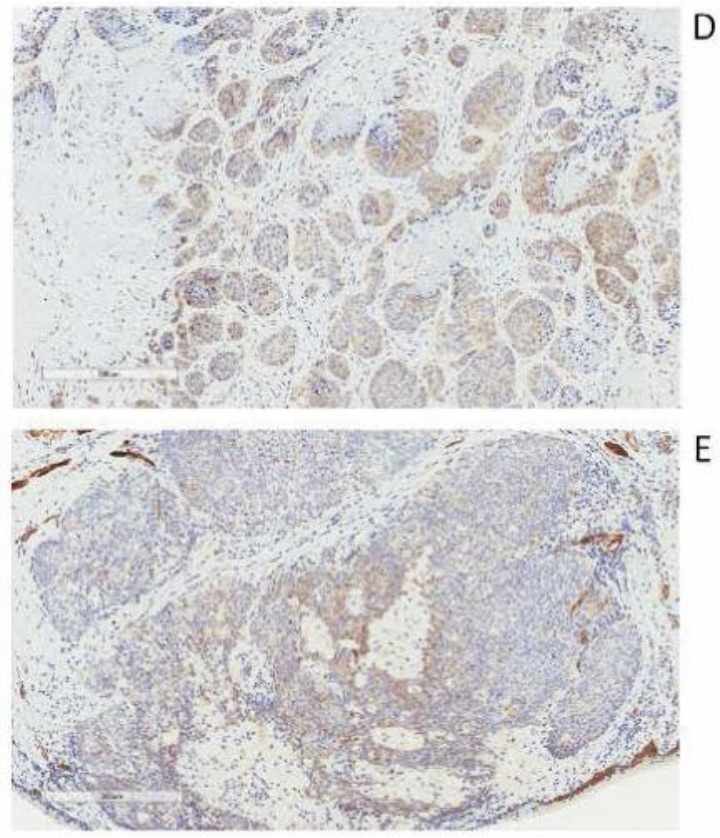

Figure 1. Immunohistochemical analysis of BAG3 expression in sebaceous gland carcinoma of the eyelid. Paraffin sections from human surgically removed sebaceous gland carcinoma of the eyelid were analyzed by immunohistochemistry using anti-BAG3 antibody. A: Case 1 (original magnification $\times 40$ ). B: Case 2 (original magnification $\times 40$ ). C: Case 3 (original magnification $\times 40$ ). D: Case 4 (original magnification $\times 40$ ). E: Case 5 (original magnification $\times 40$ ).

Table II. BAG3 expression in sebaceous gland carcinoma

\begin{tabular}{cccccc}
\hline Case & $\begin{array}{c}\text { BAG3 strongly positive } \\
3+(\%)\end{array}$ & $\begin{array}{c}\text { BAG3 moderately positive } \\
2+(\%)\end{array}$ & $\begin{array}{c}\text { BAG3 weakly positive } \\
1+(\%)\end{array}$ & $\begin{array}{c}\text { BAG3 negative rate } \\
(\%)\end{array}$ & $\begin{array}{c}\text { BAG3 positive rate } \\
\text { A total of } 1+\sim 3+(\%)\end{array}$ \\
\hline 1 & 35 & 35 & 30 & 0 & 100 \\
2 & 10 & 80 & 10 & 0 & 100 \\
3 & 0 & 0 & 80 & 20 & 80 \\
4 & 5 & 10 & 30 & 60 & 45 \\
5 & 0 & 5 & 35 & 60 \\
\hline
\end{tabular}

\section{References}

1 Takayama S, Xie Z and Reed JC: An evolutionarily conserved family of Hsp70/Hsc70 molecular chaperone regulators. J Biol Chem 274: 781-786, 1999.

2 Shields JA, Demirci H, Marr BP, Eagle RC Jr and Shields CL: Sebaceous carcinoma of the eyelids: personal experience with 60 cases. Ophthalmology 111: 2151-2157, 2004.
3 Mulay K, Aggarwal E and White VA: Periocular sebaceous gland carcinoma: A comprehensive review. Saudi J Ophthalmol 27: 159-165, 2013.

4 Choi YJ, Jin HC, Lee MJ, Kim N, Choung HK and Khwarg SI: Prognostic value of clinical and pathologic $\mathrm{T}$ stages defined by the American Joint Committee on Cancer for eyelid sebaceous gland carcinoma in Korea. Jpn J Ophthalmol 58: 327-333, 2014. 
5 Watanabe A, Sun MT, Pirbhai A, Ueda K, Katori N and Selva D: Sebaceous carcinoma in Japanese patients: clinical presentation, staging and outcomes. Br J Ophthalmol 97: 1459-1463, 2013.

6 Rao NA, Hidayat AA, McLean IW and Zimmerman LE: Sebaceous carcinomas of the ocular adnexa: a clinicopathological study of 104 cases, with five-year follow-up data. Hum Pathol 13: 113-122, 1982.

7 Chao AN, Shields CL, Krema H and Shields JA: Outcome of patients with periocular sebaceous gland carcinoma with and without conjunctival intraepithelial invasion. Ophthalmology 108: 1877-1883, 2001

8 Takamura $\mathrm{H}$ and Yamashita $\mathrm{H}$ : Clinicopathological analysis of malignant eyelid tumor cases at Yamagata university hospital: statistical comparison of tumor incidence in Japan and in other countries. Jpn J Ophthalmol 49: 349-354, 2005.

9 Esposito V, Baldi C, Zeppa P, Festa M, Guerriero L, d'Avenia M, Chetta M, Zullo F, De Laurenzi V, Turco MC, Rosati A and Guida M: BAG3 Protein Is Over-Expressed in Endometrioid Endometrial Adenocarcinomas. J Cell Physiol 232: 309-311, 2017.

10 Rosati A, Graziano V, De Laurenzi V, Pascale M and Turco MC: BAG3: a multifaceted protein that regulates major cell pathways. Cell Death Dis 2: e141, 2011.

11 Franco R, Scognamiglio G, Salerno V, Sebastiani A, Cennamo G, Ascierto PA, Botti G, Turco MC and Rosati A: Expression of the anti-apoptotic protein BAG3 in human melanomas. J Invest Dermatol 132: 252-254, 2012.

12 Rosati A, Bersani S, Tavano F, Dalla Pozza E, De Marco M, Palmieri M, De Laurenzi V, Franco R, Scognamiglio G, Palaia R, Fontana A, di Sebastiano P, Donadelli M, Dando I, Medema JP, Dijk F, Welling L, di Mola FF, Pezzilli R, Turco MC and Scarpa A: Expression of the antiapoptotic protein BAG3 is a feature of pancreatic adenocarcinoma and its overexpression is associated with poorer survival. Am J Pathol 181: 1524-1529, 2012.

13 Chiappetta G, Basile A, Barbieri A, Falco A, Rosati A, Festa M, Pasquinelli R, Califano D, Palma G, Costanzo R, Barcaroli D, Capunzo M, Franco R, Rocco G, Pascale M, Turco MC, De Laurenzi V and Arra C: The anti-apoptotic BAG3 protein is expressed in lung carcinomas and regulates small cell lung carcinoma (SCLC) tumor growth. Oncotarget 5: 6846-6853, 2014.

14 Ammirante M, Rosati A, Arra C, Basile A, Falco A, Festa M, Pascale M, d'Avenia M, Marzullo L, Belisario MA, De Marco M, Barbieri A, Giudice A, Chiappetta G, Vuttariello E, Monaco M, Bonelli P, Salvatore G, Di Benedetto M, Deshmane SL, Khalili K, Turco MC and Leone A: IKK \{gamma \} protein is a target of BAG3 regulatory activity in human tumor growth. Proc Natl Acad Sci USA 107: 7497-7502, 2010.

15 Boiani M, Daniel C, Liu X, Hogarty MD and Marnett LJ: The stress protein BAG3 stabilizes $\mathrm{Mcl}-1$ protein and promotes survival of cancer cells and resistance to antagonist ABT-737. J Biol Chem 288: 6980-6990, 2013.

16 Festa M, Del Valle L, Khalili K, Franco R, Scognamiglio G, Graziano V, De Laurenzi V, Turco MC and Rosati A: BAG3 protein is overexpressed in human glioblastoma and is a potential target for therapy. Am J Pathol 178: 2504-2512, 2011.
17 Orcurto A, Gay BE, Sozzi WJ, Gilliet M and Leyvraz S: LongTerm Remission of an Aggressive Sebaceous Carcinoma following Chemotherapy. Case Rep Dermatol 6: 80-84, 2014.

18 Joshi P, Joshi A, Norohna V, Prabhash K, Kane S and D'cruz AK: Sebaceous carcinoma and systemic chemotherapy. Indian J Med Paediatr Oncol 33: 239-241, 2012.

19 Kassis JN, Guancial EA, Doong H, Virador V and Kohn EC: CAIR-1/BAG-3 modulates cell adhesion and migration by downregulating activity of focal adhesion proteins. Exp Cell Res 312: 2962-2971, 2006.

20 Kassis JN, Virador VM, Guancial EA, Kimm D, Ho AS, Mishra M, Chuang EY, Cook J, Gius D and Kohn EC: Genomic and phenotypic analysis reveals a key role for CCN1 (CYR61) in BAG3-modulated adhesion and invasion. J Pathol 218: 495-504, 2009.

21 Iwasaki M, Homma S, Hishiya A, Dolezal SJ, Reed JC and Takayama S: BAG3 regulates motility and adhesion of epithelial cancer cells. Cancer Res 67: 10252-10259, 2007.

22 Iwasaki M, Tanaka R, Hishiya A, Homma S, Reed JC and Takayama S: BAG3 directly associates with guanine nucleotide exchange factor of Rap1, PDZGEF2, and regulates cell adhesion. Biochem Biophys Res Commun 400: 413-418, 2010.

23 Suzuki M, Iwasaki M, Sugio A, Hishiya A, Tanaka R, Endo T, Takayama S and Saito T: BAG3 (BCL2-associated athanogene 3) interacts with MMP-2 to positively regulate invasion by ovarian carcinoma cells. Cancer Lett 303: 65-71, 2011.

24 Chiappetta G, Basile A, Arra C, Califano D, Pasquinelli R, Barbieri A, De Simone V, Rea D, Giudice A, Pezzullo L, De Laurenzi V, Botti G, Losito S, Conforti D and Turco MC: BAG3 down-modulation reduces anaplastic thyroid tumor growth by enhancing proteasome-mediated degradation of BRAF protein. J Clin Endocrinol Metab 97: E115-120, 2012.

25 Habata S, Iwasaki M, Sugio A, Suzuki M, Tamate M, Satohisa S, Tanaka R and Saito T: BAG3-mediated Mcl-1 stabilization contributes to drug resistance via interaction with USP9X in ovarian cancer. Int J Oncol 49: 402-410, 2016.

26 Chuma M, Sakamoto N, Nakai A, Hige S, Nakanishi M, Natsuizaka M, Suda G, Sho T, Hatanaka K, Matsuno Y, Yokoo H, Kamiyama T, Taketomi A, Fujii G, Tashiro K, Hikiba Y, Fujimoto $\mathrm{M}$, Asaka $\mathrm{M}$ and Maeda S: Heat shock factor 1 accelerates hepatocellular carcinoma development by activating nuclear factor-kB/mitogen-activated protein kinase. Carcinogenesis 35: 272-281, 2014.

27 Yang D, Zhou J, Wang H, Wang Y, Yang G and Zhang Y: High expression of BAG3 predicts a poor prognosis in human medulloblastoma. Tumour Biol 37: 13215-13224, 2016.

Received February 22, 2017

Revised March 13, 2017

Accepted March 14, 2017 